Mr. Valentin, Mr. Mellor, of Salford, and other friends, my thanks are due for other substances.

I have already pointed out that a large portion of the work done in the last four years has consisted in the elimination of the effects of impurities. I am therefore aware of the great necessity for caution in the spectroscopic examination of various substances. There is, however, a number of bodies which permit of the inquiry into their simple or complex nature being made in such a manner that the presence of impurities will be to a certain extent negligable. I have brought this subject before the Royal Society at its present stage, in the hope that possibly others may be induced to aid inquiry in a region in which the work of one individual is as a drop in the ocean. If there is anything in what I have said, the spectra of all the elementary substances will require to be re-mapped, and re-mapped from a new standpoint ; further, the arc must replace the spark, and photography must replace the eye. A glance at the red end of the spectrum of almost any substance incandescent in the voltaic arc in a spectroscope of large dispersion, and a glance at the maps prepared by such eminent observers as Huggins and Thalen, who have used the coil, will give an idea of the mass of facts which have yet to be recorded and reduced before much further progress can be made.

In conclusion I would state that only a small part of the work to which I have drawn attention is my own. In some cases I have merely, as it were, codified the work done by other observers in other countries. With reference to that done in my own laboratory, I may here repeat what I have said before on other occasions, that it is largely due to the skill, patience, and untiring zeal of those who have assisted me. The burthen of the final reduction, to which I have before referred, has fallen to Mr. Miller, my present assistant; while the mapping of the positions and intensities of the lines was done by Messrs. Friswell, Meldola, Ord and Starling, who have successively filled that post.

I have to thank Corporal Ewings, R.E., for preparing the various diagrams which I have submitted to the notice of this Society.

\section{EXPERIMENTS IN ELECTRIC LIGHTING}

M R. LOUIS SCHWENDLER, Superintendent ElecI trician of the Government of India, has been conducting a very careful series of experiments in London on electric lighting, with a view to decide upon the advisability of introducing this method of lighting into railway stations in India. He has just published a précis of his forthcoming report, and as the experiments were conducted on thoroughly scientific principles, and solely with a view to discover the most effective method, the results attained are extremely valuable, especially when so many systems are competing for public favour:-

First, with regard to quantity of light per unit of power, unit of speed, and unit of money (first outlay). To solve this question Mr. Schwendler tried four different dynamoelectric machines producing the electric current in one direction, viz., A, medium size, B, small; as supplied by Messrs. Siemens, Brothers, of London (construction :Siemens, system :- - Hefner von Alteneck). C, workshop pattern, as supplied by Messrs. Soutter and Lemonnier, of Paris (construction:- Gramme). D, with two sets of brushes as supplied by the British Telegraph Manufactory (construction:-Gramme). Mr. Schwendler finds these four machines all sufficiently practical for the production of the electric light, but, as a rule, the statements of their actual efficiency were not found to be in conformity with the results obtained from his own experiments. The quantity of light produced by these dynamoelectric machines had been over-rated, and the amount of power consumed underrated. But, notwithstanding this, he finds that the unit of light as produced in the electric arc (disintegration) by any of the four dynamo-electric machines is at least fifty times cheaper than the unit of light as produced by combustion, considering the expenditure of power only. This represents an enormous engineering margin in favour of the electric light.

Mr. Schwendler makes a most important proviso by stating that this relation only holds good as long as one dynamo-electric machine produces one electric light; he returns to this point in a subsequent part of his careful précis.

The three dynamo-electric machines $B, C$, and $D$, he found practically equal; the dynamo-electric machine A gives a much stronger light for a comparatively smaller expenditure of power. In round numbers it may be said that dynamo-electric machine A gives about double the quantity of light given by any of the other three machines, and that only about half as much power is expended to produce the unit of light. This favourable result, $\mathrm{Mr}$. Schwendler states, is principally due to the comparatively small internal resistance of $\mathrm{A}$, and its low speed.

Secondly, with reference to constancy and regularity of the electric light, Mr. Schwendler says that this appears to be still the weak point, and many improvements in this respect are possible and desirable. He has tried. two different lamps:- $a$. The Serrin lamp, as supplied by Messrs. Soutter and Lemonnier, of Paris, and the British Telegraph Manufactory; $b$. The Siemens lamp, as supplied by Messrs. Siemens Brothers. The Serrin lamp, for any given adjustment, regulates the length of the arc only in one direction, i.e., it diminishes that length. The actual consumption of the carbon points regulates the length of the arc in the other direction, i.e., increases it. In the Siemens lamp the decrease of the length of the arc is effected exactly in the same manner as in the Serrin lamp, but the increase in the length of the arc is not only left to the consumption of the carbon points - a comparatively slow process-but is accelerated by the addition of a make and break arrangement, which separates the carbon points. Hence, from a theoretical point of view, the Siemens lamp is undoubtedly superior, since the length of the arc is rapidly adjusted in both directions, and consequently the working. currents can increase to a very considerable degree without spoiling the dynamo-electric machine. But practically Mr. Schwendler finds the Siemens lamp somewhat difficult to manage, and although, when once well adjusted, it burns as regularly as the Serrin lamp, it is far more difficult to arrive at this adjustment. For practical use he prefers, therefore, the Serrin lamp, with those alterations and constructional improvements which his own experiments have suggested. A second cause of the irregularity of the electric light is the still imperfect state of the carbon points. Of late some great improvements have been made in the manufacture of artificial carbons, but much more is required, and this point deserves the closest attention. In his final report Mr. Schwendler will treat this subject in detail. To make the electric light more steady, Mr. Schwendler states, should be considered one of the most important questions to be solved.

Thirdly, Mr. Schwendler considers the question as to how to put up the light, its position, and mechanical details. Under this head he considers the method of dividing the electric light, i.e. producing by the same electro-motor a number of lights at different points of a given space. This method, which he does not consider as yet solved, appears to him impracticable from an engineering point of view. He refers to the immense loss of strength in thus dividing the light, increasing in. enormous proportion with the increase of sub-division. Mr. Schwendler, after his careful, severe, and longextended trials, comes to the decided conclusion that the electric light can alone compete with light produced by combustion, when produced of great intensity in one 
point by one dynamo-electric machine. Endeavours to cut up the electric light into a large number of small lights, although of great interest, must, he thinks, invariably result in engineering failure, as nobody could afford to pay for the luxury received. Thus, in the opinion of so competent a judge, all methods hitherto employed for using this method of lighting in public, are failures, involving a waste of power and money, with inadequate result. Having satisfied himself of the difficulty and impracticability of the division of the electric light, Mr. Schwendler tried diffusion, i.e., a few large lights (each light produced by one machine) are placed at different points of the space, and by optical means the light is diffused over a large area. This method he finds perfectly practicable. There is naturally a large amount of light lost (by absorption), but, he states, this loss will bear a constant ratio to the total light produced, nay probably may decrease with the intensity. The actual plan by which Mr. Schwendler proposes to do it, and has done it during the trial, is to construct a silvered glass reflector in which a powerful electric light burns, throwing direct and reflected rays up to a white ceiling or any other convenient white surface. A number of such arrangements is to be put up in the most convenient places, and where they have the greatest effect. The form and size of each reflector will depend on the locality where it is to be used.

Any repairs required in course of time Mr. Schwendler believes can easily be effected by an ordinary mechanic. Only one man, he states, is actually required in each station, to take charge of the steam engine, dynamoelectric machine, lamps, and reflectors. Mr. Schwendler appends to this précis several details with reference to the adaptation of electric lighting to Indian stations, and also on some of the scientific results obtained by his experiments. Altogether his report is likely to be the most important contribution to a thorough knowledge of the public utilisation of electric lighting that has been made since the question has been resuseitated during the last year or two; and we should advise all interested in the subject to wait for his report before taking decisive steps to the adoption of any particular system.

\section{NOTES}

THE Emperor of Germany has approved of the election of Mr. Darwin and Prof. Owen as Foreign Members of the Berlin Academy of Sciences.

WE are glad to learn that M. Raoul Pictet is quite restored to health. The University of Geneva has conferred upon him the honorary degree of Doctor, and he has just been made a Chevalier of the Legion of Honour by the French Government, in recogrition of his eminent services to science, and especially of his snccessful experiments in the liquefaction of gases.

A Competrive examination is going on at the Paris Conservatoire des Arts et Métiers, for the appointment of a professor of physics and meteorology at the National School of Agriculture. The examination has been conducted on a new principle by a jury presided over by M. Boussingault. Each of the seven candidates has expounded before the jury his programme of lectures to be delivered, and each of them has in turn delivered a lecture on physics, and another on meteorology, after a prepara. tion of four hours. The competition is open to all without any condition of age, qualifications, and nationality; but the jurymen are instructed to attend, in giving their verdict, to the degrees obtained by candidates and their previous work or äiscoveries.

Tre Municipal Council of Paris has roted a subvention of 2,000 francs to M. Joseph Vinot, editor of the Ciel, for a series of popular lectures on astronomy, to be delivered at the Salle des Ecoles, rue d'Arras. Admiral Mouchez, who was present at the Iast lesson, announced to the pupils, numbering from 400 to 500 , that he will take measures to admit them to the observatory seriatim, in iorder to initiate them into the use of the large astronomical instruments so ably described by their professor. In one of the last reports read before the Paris Municipal Council it was stated that it would be necessary to establish somewhere in Paris an observatory of popular astronomy entirely devoted to the public exhibition of celestial phenomena, other establishments being entirely devoted to investigation.

PROF. S. P. THOMPSON has reprinted his valuable address on "Technical Education," given at the Social Science Con gress last October. In this time of intense depression, when trade seems to te drifting from our shores, and people are wondering how it is that other nations are outstripping us in departments that used to be considered as peculiarly British, Prof. Thompson's remarks on the ignorance of our mechanics are peculiarly appropriate. One telling instance he gives of the lamentable want of intelligent skill that prevails among workmen and manufacturers in this country :-- "I was recently informed by Prof. Graham Bell that he is about to return to America to resume his researches in telephony, his principal reason for quitting his native shores once more being that he found himself, in this country, unable to get his ideas carried out, unable to procure workmen capable of comprehending and carrying out new ideas, such workmen, in fact, as he was able to eraploy during his forr years' residence in America. He pointed to the laboratory of Mr. Edison as an example of an institution to which there is no parallel in this country, though there are several in the States, a laboratory equipped with a staff of trained workmen, Americans, Germans, or Englishmen, whose business is not to work on old lines, but to carry out and put into practical form new and untried devices. No wonder inventions multiply when inventors have so powerful an aid as this to further their designs; and, mark this, Mr. Bell returns to set up a similar laboratory because he cannot find in his native country men whose technical training would qualify them for his particular work." In a note Mr. Thompson gives the following paragraph from a letter of Prof. Graham Bell to a friend in America which has been going the round of the American press:- "If you want to know why inventors are more nume. rous in America than they are here, come and live for six months in England. If you wish to know how it feels to be brimfull of ideas, and yet to be unable to bave one of them executed, come to England. If you wish to know how it feels to have to wait for a month to have the simplest thing made, and then be charged a man's wages for two months, come to England. You will here be unable to see the interior of a workshop or to come into direct contact with your workmen, and the people seem in. capable of working except in the ruts worn by their predecessors. They are absolutely incapable of calculating any new design without the most laborious oversight from the inventor, and their masters, instead of encouraging invention, do all they can to put a stop to it by refusing admission to the workshops and charging the most exorbitant prices for experimental work, avowedly because 'they don't want such kind of work,' 'it gives more trouble than it is worth;' and 'if you must have new things made you must expect to pay for them !' It is in vain that I say I am willing to pay anything to have my work done, and that what I object to is having to pay for not having it done. $\mathrm{It}$ is the same everywhere. Not only is your work not done, but you have to wait so long for the simplest things that your ideas cool, and you get quite exasperated at your inability to do anything." The moral of all this is obvious.

THE widow of the late Prof. E. Eichwald has presented the. remarkable palæontological collections of her husband to the St. Petersburg University, which already possessed a part of them. These collections, collected by the late Prof. Fichwald since $x 825$, number no less than 30,000 specimens of fossils from 